\title{
A Derived Exposure Chart for Computed Radiography in a Negroid Population
}

\author{
Thomas Adejoh*, Odira C. Ewuzie, Joshua K. Ogbonna, Stanley O. Nwefuru, \\ Nnamdi C. Onuegbu \\ Radiology Department, Nnamdi Azikiwe University Teaching Hospital, Nnewi, Nigeria \\ Email: ‘adtoms@yahoo.com,deeraeve@yahoo.co.uk,joshuakayceogbonna@gmail.com, \\ nwefurustanley@gmail.com,onuegbun@gmail.com
}

Received 13 May 2016; accepted 12 July 2016; published 15 July 2016

Copyright (C) 2016 by authors and Scientific Research Publishing Inc. This work is licensed under the Creative Commons Attribution International License (CC BY). http://creativecommons.org/licenses/by/4.0/

(c) (7) Open Access

\section{Abstract}

Background: Computed radiography has a wider exposure latitude when compared with filmscreen imaging system. Consequently, the risk of dose creep is high. A conscientious effort is therefore, needed by the radiographer to keep exposure as low as reasonably achievable. Objective: To derive a computed radiography exposure chart for a negroid population using AGFA photostimulable phosphor plates and a GE static X-ray machine. Materials and Method: A static X-ray machine, a digitizer, and photostimulable phosphor plates were used for the X-ray examination. Chest examinations were done at a Focus-Film-Distance (FFD) of $150-180 \mathrm{~cm}$ while all other examinations were conducted at $90-100 \mathrm{~cm}$ FFD. The range of exposure factors $(\mathrm{kVp}, \mathrm{mA}$ and $\mathrm{mAs})$ used by radiographers in the centre was noted and the $90^{\text {th }}$ percentile calculated. Over a threemonth period, the patients were examined with the $90^{\text {th }}$ percentile of tube potential $(\mathrm{kVp})$ while keeping other factors constant. The $\mathrm{kVp}$ was gradually decreased and halted if radiologists and radiographers unconnected with the work expressed misgivings about the quality of the image. A similar procedure was adopted for the tube current (mA). The threshold adopted as low as reasonably achievable was the factor preceding the point of observation by other personnel. Metrics for central tendency from the statistical packages for social sciences, version 17.0 was used to analyze the data. Results: 335 subjects of both gender aged 0 - 92 years were examined by the researchers. Adult exposure factors used by the radiographers (and those derived by the researchers) had a range of $45-130 \mathrm{kVp}(62-94 \mathrm{kVp}), 63-320 \mathrm{~mA}(100-250 \mathrm{~mA})$ and $4.0-25.0 \mathrm{mAs}(5.0-$ $20.0 \mathrm{mAs}$ ) respectively. Pediatric chest (and researchers-derived) factors were 50 - $75 \mathrm{kVp}$ (52 $65 \mathrm{kVp}), 50$ - $250 \mathrm{~mA}(100-220 \mathrm{~mA})$ and 3.20 - $10.0 \mathrm{mAs}$ (3.2 - $6.5 \mathrm{mAs})$ respectively. Conclusion: Upper threshold of adult (and paediatric) exposure factors in computed radiography with comparable equipment and accessories should not exceed $94 \mathrm{kVp}$ (65 kVp), $250 \mathrm{~mA}$ ( $220 \mathrm{~mA}$ ) and 20.0 $\mathrm{mAs}$ (6.5 mAs) respectively. The derived exposure chart is also adequate to address motion unsharpness in chest examinations.

${ }^{*}$ Corresponding author. 


\section{Keywords}

\section{Computed Radiography, Exposure, Radiographer, kVp, Tube Current, X-Ray}

\section{Introduction}

Computed Radiography (CR), scientifically known as Photostimulable Phosphor (PSP) radiography, is a digital technology for the acquisition of radiographic images [1] [2]. It is the most common digital radiography modality in radiology departments today, with an estimated 7000 systems in use worldwide. As of September 2000, there were five manufacturers of CR imaging devices: Agfa, Fuji, Kodak, Konica and Lumisys. However, their photostimulable phosphor storage plates have dissimilar dose response characteristics.

This lack of calibration uniformity makes the definition of the acceptable exposure ranges for CR cumbersome [1]. Even though manufacturers have responded to this challenge by offering an Exposure Index (EI), its reliability as a feedback mechanism for CR is also questionable [3].

The opinion of radiologists appears to be the stop-gap measure. They react negatively to digital images with excessive noise but rarely complain about images with reduced noise [4] [5]. While increased noise is an indication of reduced dose, this is however, not desirable as it potentially reduces the visibility of subtle pathology [6]-[8], whereas reduced noise may be an indication of overexposure and concomitantly, increased patient dose [9] [10].

The wider exposure latitude and post-processing algorithms of digital technology mask the evidence of underexposure and overexposure [8], a characteristic recognized and exploited by radiographers who eventually fall into the error of dose creep [11]. Dose creep is recognized as a gradual increase in X-ray exposures over time that results in increased radiation dose to the patient. This occurs where judgment to determine the correct radiographic exposure factors is needed when taking into account a large range of patient sizes [9].

Since reduction in patient dose is one of the important considerations for the implementation of CR in a traditional film-based radiology department [5], eliminating dose creep is very important. One effective way to do this is to develop validated radiographic technique charts for all performed examinations. These exposure charts are an essential quality assurance component of any diagnostic X-ray department. Internationally, most countries require regular use of these charts [11].

The review of the literature reveals some exposure adaptation system. However, some are several decades old [8] [12]-[15], and they were derived with Caucasian and Asian populations.

A simple CR-specific chart derived using negroid populations from and in Africa, and which covers the most common examinations, is what this work was designed to address. This chart is specific to AGFA photostimulable phosphor plates and GE static X-ray machines manufactured not earlier than 2003. Centers with comparable machine age and ratings as well as similar photostimulable phosphor plates will find the results useful in dose optimization and quality control.

\section{Materials and Methods}

The work is a mixed design incorporating both prospective and retrospective components. It was carried out between June to September, 2015 at a teaching hospital in Nigeria. Confidentiality was maintained by omitting names, ward, address and clinical indications of the subjects during data collection.

The X-ray machine used was a GE silhouette VR, high frequency, 3-phase, static digital unit with a maximum tube potential and current of $140 \mathrm{kVp}$ and $600 \mathrm{~mA}$ respectively, and a total filtration of $2.7 \mathrm{mmAl}$. It was manufactured in 2003 and installed in 2011 by VAMED. A potter-bucky couch and erect chest stand were used. Other equipment and accessories were a CR-12-x digitizer and new $17 \times 14$ inch photostimulable phosphor imaging plates (model CRMD1.0) manufactured by Agfa Healthcare, Belgium, and installed at the teaching hospital in October, 2014.

Any patient who came for X-ray examination within the study period and could stand erect formed part of the population. Their age and gender were obtained from their request cards. Chest examinations were done at a focus-film-distance (FFD) of $150-180 \mathrm{~cm}$ while all other examinations were conducted at $90-100 \mathrm{~cm}$ FFD.

Although the researchers are staff of the centre in focus, the work was blinded to all other staff to minimize 
bias. Because of the wide exposure latitude and post-processing features of the computed radiography modality, it was observed that the radiographers in the centre did not have specific exposure parameters for different body habitus. The subjects were therefore, not categorized in accordance with body size but considered as a homogenous group.

The range of exposure factors $(\mathrm{kVp}, \mathrm{mA}$ and $\mathrm{mAs})$ used by other radiographers in the centre were noted by the researchers. Subsequently, the $90^{\text {th }}$ percentile of the factors was calculated. Over a three-month period, the patients were examined with the $90^{\text {th }}$ percentile of tube potential $(\mathrm{kVp})$ while keeping other factors constant. The $\mathrm{kVp}$ was gradually decreased and halted if radiologists and radiographers unconnected with the work expressed misgivings about the quality of the image. A similar procedure was adopted for the tube current (mA).

Descriptive statistics from the statistical packages for social sciences, version 17.0 (SPSS Incorporated, Chicago, Illinois, USA) was used to analyze the data.

\section{Results}

335 subjects of both gender aged 0 - 92 years were examined by the researchers (Table 1 ). Adult exposure factors used by the radiographers (and those derived by the researchers) had a range of $45-130 \mathrm{kVp}(62-94 \mathrm{kVp}$ ), 63 - $320 \mathrm{~mA}(100$ - $250 \mathrm{~mA})$ and 4.0 - $25.0 \mathrm{mAs}(5.0$ - $20.0 \mathrm{mAs})$ respectively. Pediatric chest (and researchersderived) factors were 50 - $75 \mathrm{kVp}(52-65 \mathrm{kVp}), 50$ - $250 \mathrm{~mA}(100-220 \mathrm{~mA})$ and 3.20 - $10.0 \mathrm{mAs}(3.2$ - 6.5 $\mathrm{mAs}$ ) respectively (Table 2). A comparison of this work with another one gave comparable results except in chest where their $\mathrm{kVp}(106)$ and $\mathrm{mAs}$ (3.33) was significantly higher than ours (73 kVp, $10 \mathrm{mAs}$ ) as shown in Table 3. Statistical analyses using one-sample t-test for both $\mathrm{mAs}(3.33 ; 10)$ and $\mathrm{kVp}(106 ; 73)$ with $\mathrm{p}<0.05$ as level of significance gave a statistically significant difference between the $\mathrm{mAs}(\mathrm{p}=0.002)$ and $\mathrm{kVp}(\mathrm{p}=0.000)$ respectively. Further correlation to determine the level of clinical significance yielded $r=0.675(\mathrm{mAs})$ and $\mathrm{r}=$ $0.236(\mathrm{kVp})$ respectively. These indicate that the difference in $\mathrm{mAs}$ is clinically significant while that in $\mathrm{kVp}$ is not clinically significant (Table 4).

\section{Discussion}

Digital technology has wider exposure latitude and post-processing algorithms which can mask the evidence of underexposure and overexposure. These characteristics have serious impact on diagnosis and patient radiation dose respectively [8]. Understanding what constitutes under-exposure and over-exposure is however, cumbersome [1], because computed radiography modality has the capability to normalize various degrees of exposure adjustment and produce a standard optical density irrespective of errors [8]. This work was an attempt to define over-exposure by revealing the minimum exposure parameters that can yield images of acceptable diagnostic quality.

Our findings show that no matter the temptation to err on the side of dose creep, a much lower $\mathrm{kVp}$, $\mathrm{mA}$ and mAs can give acceptable results (Figures i-viii). The densest anatomy can be conveniently examined with a maximum of $250 \mathrm{~mA}$ and $<94 \mathrm{kVp}$ (Table 2). This disagrees however, with the finding of a similar work where the researchers compared film/screen technology, CR and direct digital radiography, and found that CR needs a higher exposure to the patient to provide equivalent image quality to film/screen [16]. This is likely if optical

Table 1. Throughput of adult subjects examined during the study period.

\begin{tabular}{ccccc}
\hline Parameter & Male & Female & Total & \% \\
\hline Chest & 80 & 103 & 183 & 55 \\
Lumbo-sacral spine & 18 & 22 & 40 & 12 \\
Skull & 14 & 18 & 32 & 9.6 \\
Knee & 11 & 13 & 24 & 7.2 \\
Femur & 9 & 12 & 19 & 5.7 \\
Cervical spine & 6 & 13 & 19 & 5.7 \\
Pelvis/hip & 7 & 9 & 16 & 4.8 \\
Total (\%) & $\mathbf{1 4 5}(\mathbf{4 3 . 3 \% )}$ & $\mathbf{1 9 0}(\mathbf{5 6 . 7 \% )}$ & $\mathbf{3 3 5}$ & $\mathbf{1 0 0}$ \\
\hline
\end{tabular}


Table 2. Derived exposure chart.

\begin{tabular}{ccccccccc}
\hline \multirow{2}{*}{ Variable } & Age (years) & \multirow{2}{*}{ FFD (cm) } & \multicolumn{2}{c}{$\mathbf{k V p}$} & \multicolumn{2}{c}{ mAs } & \multicolumn{2}{c}{ mA } \\
\cline { 5 - 8 } & & & Range & Derived & Range & Derived & Range & Derived \\
\hline & $0-3$ & $90-100$ & $50-60$ & 52 & $3.20-6.25$ & 3.20 & $50-125$ & 100 \\
Chest (PA) & $4-9$ & 150 & $50-65$ & 55 & $3.20-6.25$ & 4.5 & $50-160$ & 140 \\
& $10-17$ & 150 & $50-75$ & 65 & $4.0-10.0$ & 6.5 & $80-250$ & 220 \\
& $21-89$ & $150-180$ & $68-82$ & 73 & $5.25-12.60$ & 10 & $160-250$ & 230 \\
Lumbo-sacral & $33-92$ & $90-100$ & $78-130$ & 94 & $8.0-25.0$ & 20 & $100-320$ & 250 \\
Pelvis & $18-88$ & $90-100$ & $70-85$ & 75 & $8.0-16.0$ & 12.8 & $80-250$ & 220 \\
Knee & $21-86$ & $90-100$ & $45-70$ & 62 & $4.0-6.30$ & 5.0 & $63-125$ & 100 \\
Femur & $24-90$ & $90-100$ & $60-85$ & 75 & $6.3-20.0$ & 10.0 & $100-250$ & 200 \\
Cervical/S (AP) & $32-87$ & $90-100$ & $63-88$ & 75 & $4.0-12.5$ & 6.4 & $50-150$ & 100 \\
Skull (OF/Lat) & $18-91$ & $90-100$ & $74-80$ & 70 & $8.0-10.0$ & 8.5 & $160-200$ & 180 \\
\hline
\end{tabular}

Table 3. Comparison of different works.

\begin{tabular}{|c|c|c|c|c|c|c|c|c|c|}
\hline \multirow{2}{*}{ Parameter } & \multicolumn{3}{|c|}{ Williams et al., 2007 (mobile unit) } & \multicolumn{3}{|c|}{ Williams et al., 2007 (static unit) } & \multicolumn{3}{|c|}{ Present study, 2015 (static unit) } \\
\hline & $\mathbf{k V p}$ & mAs & $\mathbf{m A}$ & $\mathbf{k V p}$ & mAs & - & $\mathbf{k V p}$ & mAs & $\mathbf{m A}$ \\
\hline Chest (PA) & 85 & 10 & - & 106 & 3.33 & - & 73 & 10.0 & 230 \\
\hline Femur (AP/Lat) & 55 & 10 & - & 76 & 16 & - & 75 & 10.0 & 200 \\
\hline Pelvis (AP) & 55 & 24 & - & 80 & 20 & - & 75 & 12.8 & 220 \\
\hline Cervical/S (AP) & 60 & 7.5 & - & 76 & 20 & - & 75 & 6.4 & 100 \\
\hline Cervical/S (Lat) & 65 & 15 & - & 76 & 20 & - & 75 & 6.4 & 100 \\
\hline Knee (AP) & 55 & 25 & - & 70 & 6.67 & - & 62 & 5 & 100 \\
\hline Knee (Lat) & 55 & 16 & - & 70 & 6.67 & - & 60 & 5 & 63 \\
\hline Lumbosacral/S (AP) & 75 & 48 & - & 80 & 20 & - & 94 & 20.0 & 250 \\
\hline Lumbosacral/S (Lat) & 85 & 150 & - & 80 & 80 & - & 94 & 20.0 & 250 \\
\hline Skull (AP) & 60 & 16 & - & 80 & 13.33 & - & 70 & 8.5 & 180 \\
\hline Skull (Lat) & 55 & 10 & - & 76 & 6.67 & - & 70 & 8.5 & 180 \\
\hline
\end{tabular}

Table 4. Statistical comparison of the present study with a similar work for chest parameters.

\begin{tabular}{|c|c|c|c|c|c|c|}
\hline & $\begin{array}{l}\text { Williams et al., } \\
2007\end{array}$ & $\begin{array}{c}\text { Present study, } \\
2015\end{array}$ & $\begin{array}{c}\text { One-sample } \\
\text { t-test }\end{array}$ & Remark & Pearson's correlation & Remark \\
\hline $\mathrm{kVp}$ & 106 & 73 & $\mathrm{p}=0.000$ & $\begin{array}{l}\text { Statistically } \\
\text { significant }\end{array}$ & $r=0.236$ & $\begin{array}{l}\text { Not clinically } \\
\text { significant }\end{array}$ \\
\hline mAs & 3.33 & 10 & $p=0.002$ & $\begin{array}{l}\text { Statistically } \\
\text { significant }\end{array}$ & $r=0.675$ & $\begin{array}{l}\text { Clinically } \\
\text { significant }\end{array}$ \\
\hline
\end{tabular}

$\mathrm{p}<0.05$ (level of significance).

density is the primary interest but our work shows that a comparably higher exposure may not be necessary to produce diagnostically useful images.

It has however, been shown that increasing the tube potential in chest radiography from $60 \mathrm{kVp}$ to $90 \mathrm{kVp}$ will result in a decrease in entrance surface dose (ESD) by $60 \%$ and effective dose by $20 \%$. Therefore, the use of low tube potentials for dense anatomy is discouraged [17]. Even though an image that is diagnostically useful can still be produced at a lower $\mathrm{kVp}$, the researchers were mindful of the consideration for entrance surface dose 
to start their decrease in exposure factors from the $90^{\text {th }}$ percentile and eventually arrived at a tube potential of 70 $\mathrm{kVp}$ (skull), $73 \mathrm{kVp}$ (chest), $75 \mathrm{kVp}$ (femur), $75 \mathrm{kVp}$ (pelvis) and $94 \mathrm{kVp}$ (lumbosacral) respectively (Table 3). Previous researchers however, pegged the optimum tube potential for adult chest radiography at $60 \mathrm{kVp}$ [18], and $106 \mathrm{kVp}$ [11]. The wide variation between the three works is possibly an indication of differences in subjects, training and inter-radiographer idiosyncracies.

\section{Conclusion}

Dose creep can be minimized by a computed radiography-specific exposure chart. Such a chart has been derived for a negroid population in Nigeria using AGFA photostimulable phosphor plates and a GE static X-ray machine manufactured not earlier than 2003. In addition, the upper threshold of adult exposure factors using comparable equipment and accessories is $94 \mathrm{kVp}, 250 \mathrm{~mA}$ and $20.0 \mathrm{mAs}$ respectively. The radiographer, rather than technology, is the major determinant of patient dose in view of their ability to manipulate exposure parameters.

\section{Limitation}

A comparison of our exposure chart with that of other hospitals in the locality would have given an idea into the extent of variations using comparable as well as different equipment and accessories. Unfortunately, there are no documented charts in the literature from our locality.

\section{Recommendations}

Similar works that will replicate ours should be carried out using different PSP plates than the AGFA used by us to determine the extent of variation between different receptors. In addition, the entrance skin dose level of the recommended exposure factors should be investigated to ascertain if they are within acceptable limits.

\section{Declarations}

Conflict of interest and funding: nil.

\section{References}

[1] Samei, E., Seibert, J.A., Willis, C.E., Flynn, M.J., Mah, E. and Junck, K.L. (2001) Performance Evaluation of Computed Radiography Systems. Medical Physics, 28, 361-371. http://dx.doi.org/10.1118/1.1350586

[2] Sonoda, M., Takano, M., Miyahara, J. and Kato, H. (1983) Computed Radiography Utilizing Scanning Laser Stimulated Luminescence. Radiology, 148, 833-838. http://dx.doi.org/10.1148/radiology.148.3.6878707

[3] Butler, M.L., Rainford, L., Last, J. and Brennan, P.C. (2010) Are Exposure Index Values Consistent in Clinical Practice? A Multi-Manufacturer Investigation. Radiation Protection Dosimetry, 139, 371-374. http://dx.doi.org/10.1093/rpd/ncq094

[4] Seibert, J.A., Shelton, D.K. and Moore, E.H. (1996) Computed Radiography X-Ray Exposure Trends. Academic Radiology, 3, 313-318. http://dx.doi.org/10.1016/S1076-6332(96)80247-9

[5] Freedman, E.P., Mun, S.K., La, S.C.B. and Nelson, M. (1993) The Potential for Unnecessary Patient Exposure from the Use of Storage Phosphor Imaging Systems. SPIE Medical Imaging, 1897, 472-479. http://dx.doi.org/10.1117/12.146998

[6] Thakur, Y., Bjarnason, T.A., Hammerstrom, K., Marchinkow, L., Koch, T. and Aldrich, J.E. (2012) Assessment of Patient Doses in CR Examinations throughout a Large Health Region. Journal of Digital Imaging, 25, 189-195. http://dx.doi.org/10.1007/s10278-011-9390-1

[7] Heath, R., England, A., Ward, A., et al. (2011) Digital Pelvic Radiography: Increasing Distance to Reduce Dose. Radiologic Technology, 83, 20-28.

[8] Ching, W., Robinson, J. and McEntee, M.F. (2015) DigiBit: A System for Adjusting Radiographic Exposure Factors in the Digital Era. Radiologic Technology, 86, 614-622.

[9] Gibson, D.J. and Davidson, R.A. (2012) Exposure Creep in Computed Radiography: A Longitudinal Study. Academic Radiology, 19, 458-462. http://dx.doi.org/10.1016/j.acra.2011.12.003

[10] Herrmann, T.L., Fauber, T.L., Gill, J., et al. (2012) Best Practices in Digital Radiography. Radiologic Technology, 84, 83-89.

[11] Williams, M.B., Krupinski, E.A., Strauss, K.J., Breeden, W.K., Rzeszotarski, M.S., Applegate, K., Wyatt, M., Bjork, S. 
and Seibert, J.A. (2007) Digital Radiography Image Quality: Image Acquisition. Journal of the American College of Radiology, 4, 371-388. http://dx.doi.org/10.1016/j.jacr.2007.02.002

[12] Fauber, T.L., Cohen, T.F. and Dempsey, M.C. (2011) High Kilovoltage Digital Exposure Techniques and Patient Dosimetry. Radiologic Technology, 82, 501-510.

[13] Simon, M. (1956) Exposure Factor Selection by Means of a New Calculator. British Journal of Radiology, 29, 588595. http://dx.doi.org/10.1259/0007-1285-29-347-588

[14] Gyss, E.E. (1957) A Medical Radiographic Technique Chart Based on Constants. X-Ray Technician, 29, 76-80.

[15] Power, K.J. (1959) A Simple Measuring Device for the Busy Department. Radiographer, 7, 16-17.

[16] Compagnone, G., Baleni, M.C., Pagan, L., Calzolaio, F., Barozzi, L. and Bergamini, C. (2006) Comparison of Radiation Doses to Patients Undergoing Standard Radiographic Examinations with Conventional Screen-Film Radiography, Computed Radiography and Direct Digital Radiography. British Journal of Radiology, 79, 899-904. http://dx.doi.org/10.1259/bjr/57138583

[17] Martin, C.J., Darragh, C.L., McKenzie ,G.A. and Bayliss, A.P. (1993) Implementation of a Programme for Reduction of Radiographic Doses and Results through Increase in Tube Potential. British Journal of Radiology, 66, 228-233. http://dx.doi.org/10.1259/0007-1285-66-783-228

[18] Ma, W.K., Hogg, P., Tootell, A., Manning, D., Thomas, N., Kane, T. and Kelly, J. (2013) Anthropomorphic Chest Phantom Imaging: The Potential for Dose Creep in Computed Radiography. Radiography, 19, 207-211. http://dx.doi.org/10.1016/j.radi.2013.04.002

\section{Submit or recommend next manuscript to SCIRP and we will provide best service for you:}

Accepting pre-submission inquiries through Email, Facebook, Linkedin, Twitter, etc A wide selection of journals (inclusive of 9 subjects, more than 200 journals)

Providing a 24-hour high-quality service User-friendly online submission system

Fair and swift peer-review system

Efficient typesetting and proofreading procedure

Display of the result of downloads and visits, as well as the number of cited articles

Maximum dissemination of your research work

Submit your manuscript at: http://papersubmission.scirp.org/ 